\title{
Cellular Fatty Acid Profiles as an Aid to the Classification of "Corroding Bacilli" and Certain Other Bacteria ${ }^{1}$
}

\author{
GABRIELLE PREFONTAINE ${ }^{2}$ and F. L. JACKSON \\ Department of Medical Bacteriology, University of Alberta, \\ Edmonton, Alberta, Canada
}

\begin{abstract}
A collection of gram-negative, asporulating organisms, including corroding bacilli, was divided into four groups on the basis of a gas-liquid chromatographic analysis of the esters of their cellular fatty acids. Group I contains strains which produce hexadecanoic and octadecenoic acids as major constituents, with a lower percentage of 9-hexadecenoic acid and relatively small amounts of dodecanoic, tetradecanoic, and octadecanoic acids. Group II strains produce a large amount of octadecenoic acid and small amounts of hexadecanoic, dodecanoic, tetradecanoic, and octadecanoic acids. Strains placed in group III produced a large amount of an unidentified fatty acid, which appears to be unique to this group. Other fatty acids, including hexadecanoic, octadecanoic, and two additional unidentified acids, were produced in small amounts. Group IV contains strains which produce high contents of 9-hexadecenoic and hexadecanoic acids and a small amount of tetradecanoic acid. The facultatively anaerobic corroding organisms, including Eikenella corrodens (Eiken) Jackson and Goodman, fall into group I, whereas group II contains anaerobic strains which are distinct from each other as well as from the Bacteroides strains included in this study.
\end{abstract}

The use of cellular fatty acid profiles and metabolic end products as criteria for establishing taxonomic relationships among microorganisms has received increased emphasis since Abel, DeSchmertzing, and Peterson (1) successfully differentiated between the families $E n$ terobacteriaceae, Bacillaceae, Micrococcaceae, and Parvobacteriaceae by comparing the chromatograms of the fatty acid methyl esters of the lipids extracted from selected representatives of each of these families. Bassette and Claydon (Abstr., J. Dairy Sci. 48:475) characterized some bacteria by analysis of head-space vapors from milk cultures, and Bawden and Bassette (3) differentiated between isolates of Escherichia coli and Aerobacter aerogenes by analysis of their metabolic end products.

The taxonomic position of certain gram-negative, nonsporing "corroding bacilli" described by Eiken (6) and by Khairat (17) has been disputed $(10,14)$. We therefore decided to determine to what extent fatty acid composition would permit major groups and strains to be distinguished in a collection of organisms, including strains of corroding bacilli and certain other gram-negative bacteria, and to assess the reproducibility of the tests and their sensitivity to change of growth conditions, bearing in mind that variations in fatty acid profiles due to nutritional and environmental factors have been reported $(5,18,21)$.

The name Bacteroides corrodens was proposed by Eiken (6) for a species of corroding bacilli which included both anaerobic and facultatively anaerobic strains. Subsequently, strain 333/54-55 $\quad(=$ ATCC $23834=$ NCTC 10596), a facultative anaerobe, was designated as the type strain $(10,11)$. Recently, the facultatively anaerobic strains previously referred to as $B$. corrodens, including the type strain, were transferred to a new genus, Eikenella, under the name E. corrodens (13). In the present paper, Eikenella corrodens (Eiken) Jackson and Goodman (13) is used to refer to the facultatively anaerobic strains of corroding bacilli, including organisms referred to elsewhere as "HB-1." The anaerobic strains previously placed in the species $B$. corrodens were

\footnotetext{
${ }^{1}$ Presented in partial fulfillment of the requirements for the M.Sc. degree, 1970.

${ }^{2}$ Present address: Division of Biological Sciences, National Research Council of Canada, Ottawa, Ontario, Canada.
} 
not included in the genus Eikenella and belong to the genus Bacteroides.

\section{MATERIALS AND METHODS}

Organisms. Twenty-six gram-negative strains were used (Table 1). Strains EDMH1, UAH1, UAH2, and B912, and the $E$. corrodens strains have been described elsewhere (14).
Growth media and cultural procedures. For fatty acid analysis, all organims were grown anerobically on a modified form of the medium for Bacteroidaceae described by Wahren and Holme (24). The L-cystine content was reduced from $0.05 \%$ to $0.005 \%$, because growth of some of the corroding bacilli was inhibited by the higher concentration. Methylene blue indicator was omitted because it inhibited the facultatively

TABLE 1. Strains of bacteria examined

\begin{tabular}{|c|c|c|c|}
\hline Organisms & $\begin{array}{c}\text { DNA } \\
\text { moles \% GC }\end{array}$ & Source & Obtained from \\
\hline \multicolumn{4}{|l|}{$\begin{array}{l}\text { Eikenella corrodens (Bacteroides } \\
\quad \text { corrodens) }\end{array}$} \\
\hline NCTC $10596($ ATCC 23834) & 57.9 & Sputum & NCTC \\
\hline $\mathrm{A} 40 / 68 \ldots \ldots \ldots \ldots \ldots$ & 57.9 & Brain abscess & NCTC \\
\hline 53P (NCTC 10647) & 57.7 & Sputum & Our collection \\
\hline $53 \mathrm{~W}$ & 57.5 & (Variant of 53P) & Our collection \\
\hline S209 & 57.3 & Sputum & Our collection \\
\hline B916 & 56.9 & Not stated & $\begin{array}{l}\text { S. M. Finegold, } \\
\text { Los Angeles, Calif. }\end{array}$ \\
\hline \multicolumn{4}{|l|}{ Anaerobic "corroding bacilli" } \\
\hline EDMH $1 \ldots \ldots \ldots \ldots$ & 28.0 & Amniotic fluid & $\begin{array}{l}\text { Misericordia Hospital, } \\
\text { Edmonton, Canada }\end{array}$ \\
\hline UAH1 & 29.7 & Face lesion & Our collection \\
\hline $\mathrm{UAH} 2$. & 28.0 & Heel lesion & Our collection \\
\hline B912. & 28.3 & Not stated & $\begin{array}{l}\text { S. M. Finegold, } \\
\text { Los Angeles, Calif. }\end{array}$ \\
\hline 3936 & 38.9 & Sputum & Our collection \\
\hline 4482 & 38.3 & Neck lesion & Our collection \\
\hline \multicolumn{4}{|l|}{ Bacteroides species } \\
\hline B. fragilis NCTC 9343 & 42.2 & Appendix abscess & NCTC \\
\hline B. fragilis EB ....... & 43.0 & Not stated & $\begin{array}{l}\text { E. Bergen, University of } \\
\text { Alberta, Edmonton, } \\
\text { Canada }\end{array}$ \\
\hline B. melaninogenicus $\mathrm{GP}$ & 41.0 & Wound swab & Our collection \\
\hline \multicolumn{4}{|l|}{ Pasteurella multocida ${ }^{b}$} \\
\hline $10456-56 \mathrm{~A} \ldots \ldots$ & 41.7 & Sputum & $\begin{array}{l}\text { Yvonne E. Goodman, } \\
\text { our Department }\end{array}$ \\
\hline $5568-61 \mathrm{~A}$ & 41.4 & Sputum & \\
\hline 675-59D . & 39.0 & Sputum & \\
\hline $10955-55 \mathrm{D}$ & 40.8 & C.S.F. & \\
\hline $5228-58 \mathrm{NT}$ & 41.1 & Cat bite & \\
\hline MU3004-58NT & 40.9 & Peritonitis & \\
\hline M191-60NT ... & 40.5 & Dog bite & \\
\hline $64 C \ldots \ldots$ & 40.2 & Dog & \\
\hline \multicolumn{4}{|l|}{ P. haemolytica } \\
\hline 201000 & 39.0 & Godl & \\
\hline $\begin{array}{l}\text { P. (Yersinia) pseudo- } \\
\text { tuberculosis PL }\end{array}$ & 48.2 & (Stock strain) & $\begin{array}{l}\text { Provincial Laboratory of } \\
\text { Public Health, Edmonton, } \\
\text { Canada }\end{array}$ \\
\hline $\begin{array}{l}\text { Haemophilus aphrophilus } \\
\quad \text { NCTC } 5886 \ldots \ldots \ldots\end{array}$ & 41.3 & Endocarditis & NCTC \\
\hline
\end{tabular}

${ }^{a}$ ATCC, American type culture collection, Rockville, Md.; NCTC, National Collection of Type Cultures, London, England.

${ }^{b}$ A, Hemagglutination type A: D, hemagglutination type D; NT, nontypable. 
anaerobic strains of corroding bacilli. Because the corroding strains grew poorly in liquid media, $1.5 \%$ agar was added, and the organisms were grown on the surface of a solid medium. The addition of $1.012 \mathrm{M}$ $\mathrm{NaHCO}_{3}$, as described by Gibbons and MacDonald (7), improved growth. Organisms maintained on the medium were transferred to 50 to 100 plates and incubated anerobically at $37 \mathrm{C}$ in Baird and Tatlock cold catalyst jars which were evacuated and filled with a mixture of $90 \% \mathrm{H}_{2}$ and $10 \% \mathrm{CO}_{2}$. The Bacteroides species and the corroding strains were incubated for $72 \mathrm{hr}$, and the Pasteurella strains were incubated for $48 \mathrm{hr}$. Cells were harvested in $0.04 \mathrm{M}$ phosphate-buf-

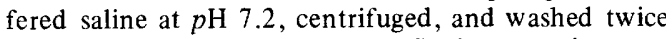
with the buffered saline. The final suspension was centrifuged at $17,300 \times g$ for $12 \mathrm{~min}$, the supernatant fluid was removed, and the packed cells were stored at $-20 \mathrm{C}$ until extracted. Preliminary studies indicated the presence of trace amounts of fatty acid in samples of medium, but the quantity was too small to have a significant effect on the results reported here.

Extraction of cellular fatty acids and preparation of methyl esters. The extraction technique was based on that described by Kaneda (16). Packed cells were thawed, and weighed amounts $(0.5$ to $1.5 \mathrm{~g})$ were suspended in $25 \mathrm{ml}$ of $1 \%$ methanolic $\mathrm{KOH}$ solution and refluxed at $68 \mathrm{C}$ for $4 \mathrm{hr}$. The resulting supernatant fluid was extracted three times with $15 \mathrm{ml}$ of $n$-hexane to remove neutral and basic materials. The aqueous phase was acidified to $p \mathrm{H} 2.0$ with concentrated $\mathrm{HCl}$ and extracted four times with $15 \mathrm{ml}$ of $n$-hexane. The extracts were pooled and evaporated to $0.5 \mathrm{ml}$ in a rotary flash evaporator. The fatty acids were methylated with $1 \mathrm{ml}$ of boron trifluoride in methanol $(14 \%, w / v)$ by heating for $2 \mathrm{~min}$ in a boiling-water bath. After adding $4 \mathrm{ml}$ of distilled water, the mixture was extracted three times with 10 $\mathrm{ml}$ of $n$-hexane. The combined extracts were evaporated to approximately $0.1 \mathrm{ml}$ and stored in Tefloncapped vials at $-20 \mathrm{C}$. Control runs were performed on all materials and reagents for gas-liquid chromatography analysis.

Gas-liquid chromatography analysis of cellular fatty acids. The fatty acid methyl esters were analyzed on a Carlo Erba Fractovap model GV dual-column gas chromatograph equipped with a hydrogen-flame ionization detector and with a strip-chart recorder using an Infotronic CR 100 digital integrator. Separation was effected on a 3-m silicone gum rubber column, $3 \%$ SE30 on Chromosorb G.AW-DMCS, 60 to 70 mesh packed in 6-mm outer diameter stainless-steel tubing. Operating conditions: injection temperature, $260 \mathrm{C}$; detector temperature, $280 \mathrm{C}$; column temperature linearly programmed from 150 to $250 \mathrm{C}$ at $3 \mathrm{C}$ per min; carrier gas, nitrogen at $50 \mathrm{ml} / \mathrm{min}$; hydrogen adjusted to give maximum sensitivity; air, $300 \mathrm{ml} / \mathrm{min}$; input and output attenuation, $10^{2}$ and 16 , respectively; chart speed, $0.5 \mathrm{inch} / \mathrm{min}$. For routine analysis, 3 to $4 \mu$ liters of the methyl esters was analyzed for 33 min under the above-stated conditions. This time interval was sufficient to detect straight-chain saturated and unsaturated methyl esters of fatty acids $\mathrm{C}_{6}$ to $\mathrm{C}_{22}$. Fatty acid quantities were determined from integrator data, and the relative percentage of each acid was calculated. For identification purposes, the samples were also analyzed on a $7.5-\mathrm{m}$ diethylene glycol succinate column, $6 \%$ DEGS on Chromosorb G, AW-DMCS, 60/70 mesh packed in 4.7-mm outer diameter copper tubing. The operating conditions were: injection and detector temperatures, $220 \mathrm{C}$; column temperature linearly programmed from 150 to $200 \mathrm{C}$ at $3 \mathrm{C}$ per min; carrier gas, nitrogen at 40 $\mathrm{ml} / \mathrm{min}$; hydrogen adjusted to give maximum sensitivity; air, $300 \mathrm{ml} / \mathrm{min}$; input and output attenuation, $10^{2}$ and 16 , respectively; chart speed, $0.5 \mathrm{inch} / \mathrm{min}$.

Identification of cellular fatty acids. The fatty acid methyl esters were tentatively identified by: (i) direct comparison of their retention times with those of standard fatty acid methyl esters chromatographed under identical gas-liquid chromatography conditions; (ii) chromatography on both polar and nonpolar columns to identify unsaturated compounds by the shift in their position in relation to saturated compounds; and (iii) chromatography of bromo derivatives (on SE-30) to confirm identification of unsaturated fatty acids (15). Positive identification of some of the major fatty acids was accomplished by combined gas chromatography-mass spectrometry. Fragmentation patterns of some components were impossible to analyze because they either were present in amounts too small to be properly identified or gave complex mass spectral scans for which no characteristic fragmentation patterns were available in the literature consulted (4). Those components which could not be identified are referred to by retention values or, more specifically, by "carbon number" or "equivalent chain length" (ECL) (8).

\section{RESULTS AND DISCUSSION}

Duplicate extracts of each bacterial strain were prepared by carrying separate inocula through the entire growth, harvest, extraction, and methylation procedures, and the extracts were chromatographed separately to assess possible variation between replicates of each culture. In $96 \%$ of the comparisons of corresponding peaks, variation of either from the arithmetic mean of the two was not greater than $\pm 2 \%$. In $2 \%$ of comparisons, the variation was from \pm 2 to $\pm 3 \%$, and an occasional variation of $\pm 4 \%$ was encountered. In Table 2 , the percentage given is the arithmetic mean from duplicate cultures.

Analysis of cellular fatty acids. The organisms were separated into four major groups by visual comparison of their fatty acid-methyl ester profiles (Fig. 1). The groups were distinguished by the presence, or absence, and the relative sizes of the major peaks.

Group I contained hexadecanoic and octadecenoic acids as major constituents, with a lower percentage of 9-hexadecenoic acid and relatively small amounts of dodecanoic, tetra- 


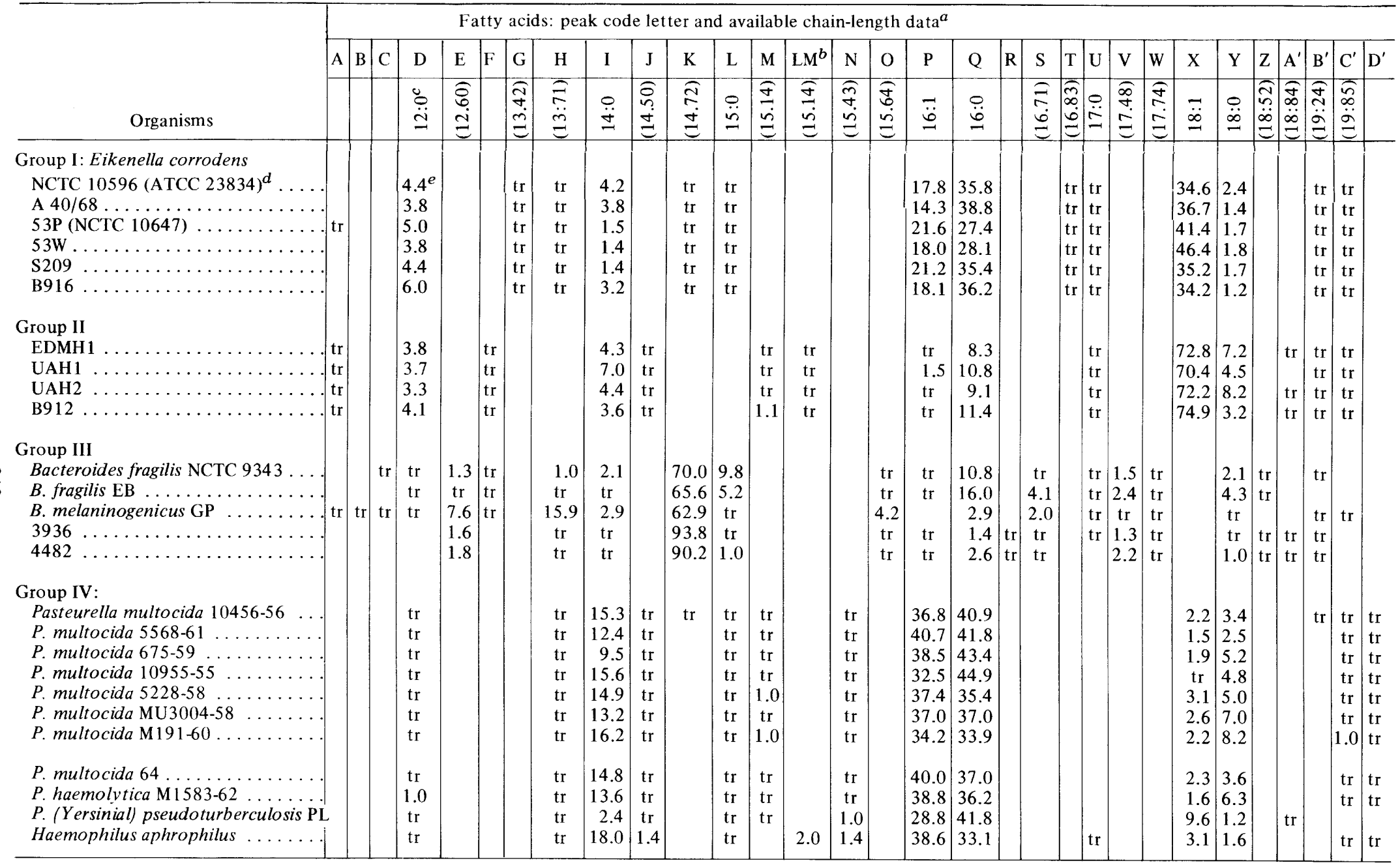

\footnotetext{
${ }^{a}$ Peaks arranged in order of increasing retention time (left to right).

${ }^{b}$ Peaks incompletely resolved, $\mathrm{M}$ was major component.
}

${ }^{c}$ When numbers not in parentheses, larger number before colon indicates number of carbon atoms, 0 or 1 after colon indicates number of double bonds. Numbers in parentheses indicate equivalent chain length of unidentified fatty acids. tr, Less than $1 \%$ of total fatty acids.

${ }^{d}$ ATCC, American Type Culture Collection, Rockville, Md.; NCTC, National Collection of Type Cultures, London, England

${ }^{e}$ Figures opposite each organism give concentration of fatty acids indicated by peak-code letter and chain-length data at top of table. Concentrations are expressed as percentages of the total content for the strain of organism. Values are arithmetic means from duplicate determinations. 

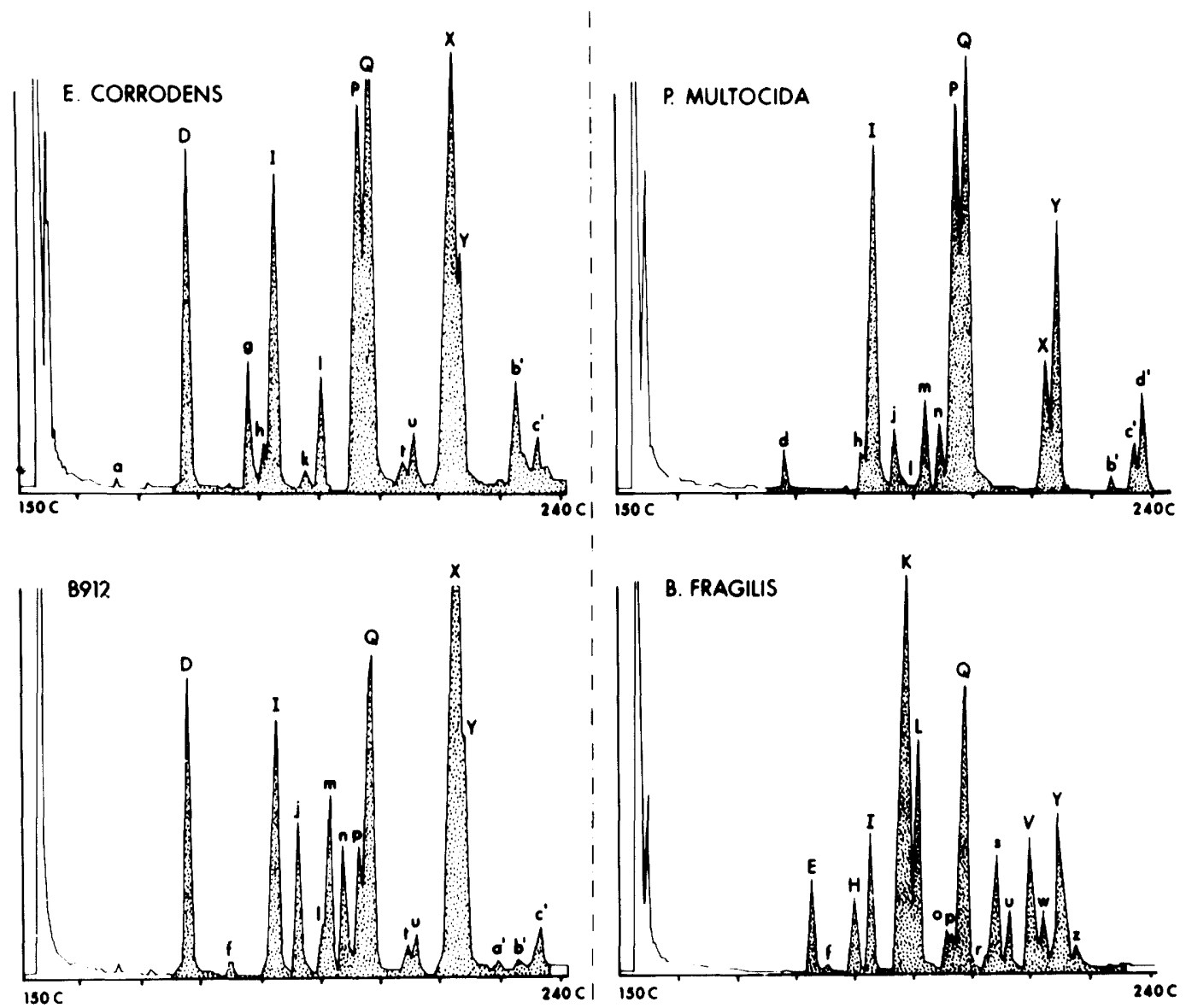

FIG. 1. Gas chromatograms (log attenuated plots) of cellular fatty acids of organisms representative of the four groups. Group I, Eikenella corrodens NCTC 10596; Group II, B912; Group III, Bacteroides fragilis NCTC 9343; Group IV, Pasteurella multocida 10955-55.

decanoic, and octadecanoic acids. The most obvious distinguishing feature of this group, compared with other groups, was that hexadecanoic and octadecenoic acids were present in significant concentration, whereas they were present in only trace amounts in groups II and III, although they were major components in group IV.

Group II was distinguished from other groups by the high content of octadecenoic acid and small amounts of hexadecanoic, dodecanoic, tetradecanoic, and octadecanoic acids. It differed from group $I$ in that it had only one major peak, and in this respect it resembled group III.

Characteristic of group III was its high content of an unidentified fatty acid, corresponding to peak $\mathrm{K}(E C L=14.72)$, which appeared to be unique to this group. Other fatty acids, including hexadecanoic, octa- decanoic, and two other unidentified acids, were present in small amounts.

Group IV was characterized by a high content of 9-hexadecenoic and hexadecanoic acids and a smaller content of tetradecanoic acid. It resembled group $I$ in that it had two major fatty acids but differed from it in that the major fatty acids were 9-hexadecenoic and hexadecanoic and not hexadecanoic and octadecenoic acids, as in group I.

Quantitative comparisons of the proportions of the principal fatty acids from each strain supported the grouping made by visual inspection of chromatograms (Table 2).

The facultatively anaerobic strains of corroding bacilli making up group I and the anaerobic strains comprising group II were shown to be distinct from each other and from the $\mathrm{Bac}$ teroides species included in this study. This is consistent with differences between these or- 
ganisms in certain biochemical characteristics and in deoxyribonucleic acid (DNA) guanine plus cytosine (GC) content (14). Differences in the fatty acid patterns of the facultatively anaerobic strains permitted differentiation of $53 \mathrm{P}$ and its variant $53 \mathrm{~W}$ from the other four strains investigated, because these two strains had a significantly greater content of octodecenoic acid with a concomitant decrease in hexadecanoic acid. The fatty acid patterns of the anaerobic strains of group II were essentially similar to each other, hence differentiation within this group was not possible.

Group I strains ( $E$. corrodens), including the ty pe strain of $E$. corrodens, NCTC 10596 , are all facultatively anaerobic, and by definition, although some strains of $B$. fragilis can tolerate up to $8 \%$ oxygen (18), facultatively anaerobic organisms are not at present admitted to the genus Bacteroides. The status of these strains has been discussed in detail by Jackson and Goodman (13), and the fatty acid profiles lend further support to separation of these organisms from those in the genus Bacteroides.

The organisms placed in group II are the four anaerobic strains of corroding bacilli: B912, EDMH-1, UAH1, and UAH2. These strains were grouped together on the basis of the large content of octadecenoic acid, which varied from 70.4 to $74.9 \%$ (Table 2 ). The next most abundant fatty acid, hexadecanoic, varied from 8.3 to $11.4 \%$. Dodecanoic, tetradecanoic, and octadecanoic acids were present in low and variable concentrations. Unlike the Bacteroides species included in the present study, and unlike strains 3936 and 4482, they do not contain the component giving peak $\mathrm{K}$ $(\mathrm{ECL}=14.72)$.

Group III contains three representatives of the genus Bacteroides, namely $B$. fragilis NCTC 9343, the strain labeled $B$. fragilis EB (a nonxylose fermenter), and $B$. melaninogenicus GP, together with the two anaerobic strains 3936 and 4482 . Strains 3936 and 4482 grew on blood-agar plates as pitting or "corroding" colonies, but they differed from the other four anaerobic corroding bacilli in DNA moles \%GC. In addition, strains 3936 and 4482 attacked glucose and a number of other substrates to produce acid, whereas the other strains of anaerobic corroding bacilli did not. The greater proportion of an unidentified fatty acid $(E C L=14.72)$ in strains 3936 and 4482 as compared with that in the other strains was unique to this group (Table 2). The organisms included in this group are not as homogeneous in their fatty acid composition as those in groups I and II. Hexadecanoic acid accounted for $10.8 \%$ and $16.0 \%$ of the total fatty acids of $B$. fragilis NCTC 9343 and $B$. fragilis $\mathrm{EB}$, respectively, whereas it represented $2 \%$ or less of the total fatty acids of $B$. melaninogenicus GP, and of strains 3936 and 4482 . On the other hand, B. melaninogenicus contained $5.9 \%$ of a second unidentified acid $(E C L=13.71)$; this represented $1 \%$ or less of the total fatty acids of the other strains in this group. Moreover, $B$. melaninogenicus GP contained significant concentrations of two more unidentified fatty acids $(E C L=12.60$ and 15.64) which were present in much lower concentrations in the other strains. Ifkovits and Ragheb (12) reported heterogeneity in cellular fatty acid patterns among members of the genus Bacteroides.

All the Pasteurella strains and Yersinia pseudotuberculosis PL were placed in group IV. This group was characterized by high and almost equal contents of 9-hexadecenoic and hexadecanoic acids. The next most abundant fatty acid was usually tetradecanoic; this was followed by variable amounts of octadecenoic and octadecanoic acids (Table 2). No qualitative differences in the fatty acid compositions among the different serotypes of $P$. multocida strains were found. $Y$. pseudotuberculosis $\mathrm{PL}$ was easily distinguishable from the other strains in this group by its possession of an unidentified acid $(E C L=16.83)$ with a concomitant decrease in the percentage of 9-hexadecenoic acid. This unidentified fatty acid was unique to $Y$. pseudotuberculosis PL. The proportion of octadecenoic acid was greater than that present in the other species of Pasteurella. This independent position of $Y$. pseudotuberculosis PL strain is in keeping with previous reports $(21,23)$ on differences between Pasteurella and Yersinia.

The profile of Haemophilus aphrophilus NCTC 5886 resembled that of the $P$. multocida strains more closely than it resembled that of $Y$. pseudotuberculosis PL.

A comparison of the fatty acid composition of the strains examined in this study is presented in Table 3 , which gives a signature or fingerprint for each strain prepared as described by Henis et al. (9). Gross distinctions can be made between each group by considering the presence or absence of letters representing major fatty acids. Differentiation between strains is not always possible within a group; however, this might in some instances be achieved by application of statistical analysis (9) to determine whether the values for the fatty acids of strains are significantly different from each other.

On the basis of constituent fatty acid spectra, 
I ABLE 3. Signatures of bacteria based on cellular fatty acid composition

\begin{tabular}{|c|c|c|}
\hline Group & Organism & Signature $^{a}$ \\
\hline I & $\begin{array}{l}\text { Bacteroides corrodens NCTC } 10956(333 / 54-55 ; \text { ATCC } 23834)^{b} \\
\text { B. corrodens NCTC A40/68 } \\
\text { B916 } \\
\text { S209 } \\
\text { 53P (NCTC 10647) } \\
\text { 53W }\end{array}$ & $\begin{array}{l}\text { QXPDIY-ghkltub'c } c^{b} \\
\text { QXPDIY-ghkltub'c' } \\
\text { QXPDIY-ghkltub'c' } \\
\text { QXPDYI-ghltub'c } c^{\prime} \\
\text { XQPDYI-aghkltub' } c^{\prime} \\
\text { XQPDYI-ghkltub'c' }\end{array}$ \\
\hline II & $\begin{array}{l}\text { B912 } \\
\text { UAH2 } \\
\text { EMDH1 } \\
\text { UAH1 }\end{array}$ & $\begin{array}{l}\text { XQDIY(ML)-afjnpua' } b^{\prime} c^{\prime} \\
\text { XQYID-afj(lm)npua' } b^{\prime} c^{\prime} \\
\text { XQYID-afj(lm)npua' } b^{\prime} c^{\prime} \\
\text { XQYIDP-afj(lm)nub' } c^{\prime}\end{array}$ \\
\hline III & $\begin{array}{l}3936 \\
4482 \\
\text { B. fragilis NCTC } 9343 \\
\text { B. fragilis } \mathrm{EB} \\
\text { B. melaninogenicus GP }\end{array}$ & $\begin{array}{l}\text { KEQV-himoprsuwyxa'b' } \\
\text { KQVEY-hioprswza'b' } \\
\text { KQLIYVEH-cdfopsuwzb' } \\
\text { KQLYS V-defhiopuwz } \\
\text { KHEOIQS-abcdfluvwyb'c' }\end{array}$ \\
\hline IV & $\begin{array}{l}\text { Pasteurella multocida A (10456-56) } \\
\text { P. multocida A (5568-61) } \\
\text { P. multocida D (675-59) } \\
\text { P. multocida D (10955-55) } \\
\text { P. multocida NT (5228-58) } \\
\text { P. multocida NT (MU3004-58) } \\
\text { P. multocida NT (M191-60) } \\
\text { P. multocida } 64 \\
P . \text { haemolytica NCTC 5885 } \\
\text { P. pseudotuberculosis PL } \\
\text { Haemophilus aphrophilus NCTC } 5886\end{array}$ & $\begin{array}{l}\text { QPIYX-dhjklmnb'c }{ }^{\prime} d^{\prime} \\
\text { QPIYX-dhjlmnc'd' } \\
\text { QPIYX-dhjlmnc'd } \\
\text { QPIY-dhjlmnc'd' } \\
\text { PQIYXM-dhjlnc'd' } \\
\text { PQIYX-dhijlmnc'd } \\
\text { PQIYXMC'-dhjnd' } \\
\text { PQIYX-dhjlmnc'd' } \\
\text { PQIYXD-hjlmnc'd } \\
\text { QPTXIYN-dhilma' } \\
\text { PQIXMJNEu }\end{array}$ \\
\hline
\end{tabular}

\footnotetext{
${ }^{a}$ Peaks arranged in decreasing order of magnitude; lower-case letters represent trace amounts (less than $1 \%$ of total) and are listed in alphabetical order; underlined letters signify that the fatty acids represented were present in equal amounts. Peaks represented by $(\mathrm{ML})$ or $(\mathrm{lm})$ were not completely resolved from one another; $\mathrm{M}$ or $\mathrm{m}$ was the major contributing peak.

$b$ ATCC, American Type Culture Collection, Rockville, Md.; NCTC, National Collection of Type Cultures, London, England.
}

B. fragilis NCTC 9343 and the strain labeled $B$. fragilis $\mathrm{EB}$ were very similar, but in semisolid agar medium $B$. fragilis $\mathrm{EB}$ did not ferment xylose. When received by us, $B$. fragilis $\mathrm{EB}$ was labeled $B$. oralis, but it is not inhibited by bile, and we have found that its fatty acid profile differs significantly from that of $B$. oralis ATCC 15930. We therefore regard strain EB as a nonxylose-fermenting biotype of $B$. fragilis.

$B$. melaninogenicus GP differed from the other Bacteroides strains in the distribution of its fatty acids. The independent position of $B$. melaninogenicus has been suggested by Rosebury (20) and supported by a numerical taxonomic of Bacteroidaceae carried out by Barnes (2).

The fatty acid profiles of strains 3936 and 4482 were virtually identical. They appear to have a greater similarity to the Bacteroides species than to the other anaerobic corroding bacilli, and this is in keeping with their DNA GC content.

Conclusions. The results of the present study demonstrate that the corroding bacilli can be conveniently divided into four groups on the basis of gas-liquid chromatography analysis of the esters of their cellular fatty acids.

It is important to recognize that studies of lipids, to be of value in taxonomy, must be carried out under strictly controlled conditions. If careful attention is paid to preparation of organisms, extraction, and gas-liquid chromatography techniques, determination of cellular fatty acids is in some circumstances a useful addition to other methods available for differentiation of bacterial species and genera.

\section{ACKNOWLEDGMENTS}

We thank L. Howard, of the Department of Medical Bacteriology, for much valuable assistance with gas 
chromatography, and the Department of Chemistry, University of Alberta, for making available facilities for mass spectrometry.

We are also indebted to Diane Rhodes, who has permitted us to quote the DNA moles\% GC from her M.Sc. thesis, the work for which was carried out in the Department of Medical Bacteriology, University of Alberta, under the supervision of one of the present authors (F. L. J.).

\section{LITERATURE CITED}

1. Abel, K., H. DeSchmertzing, and J. I. Peterson. 1963. Classification of microorganisms by analysis of chemical composition. I. Feasibility of utilizing gas chromatography. J. Bacteriol. 85:1039-1044.

2. Barnes, E. M. 1968. The relationships of bacteria within the family Bacteroidaceae as shown by numerical taxonomy. J. Gen. Microbiol. 51:313-324.

3. Bawden, R. E., and R. Bassette. 1966. Differentiation of Escherichia coli and Aerobacter aerogenes by gas-liquid chromatography. J. Dairy Sci. 49:624-627.

4. Cornu, A., and R. Massot. 1966. Compilation of mass spectral data. Heyden \& Son Ltd., London.

5. Dunlap, K. R., and J. J. Perry. 1967. Effect of substrate on the fatty acid composition of hydrocarbon-utilizing microorganisms. J. Bacteriol. 94:1919-1923.

6. Eiken, M. 1958. Studies on an anerobic rodshaped Gram-negative microorganism Bacteroides corrodens. Acta Pathol. Microbiol. Scand. 43:404-416.

7. Gibbons, R. J., and J. B. MacDonald. 1961. Degradation of collagenous substrates by $\mathrm{Bac}$. teroides melaninogenicus. J. Bacteriol. 81:614-621.

8. Harris, W. E., and H. W. Habgood. 1966. Programmed temperature gas chromatography. John Wiley \& Sons, Inc., New York.

9. Henis, Y., J. R. Gould, and M. Alexander. 1966. Detection and identification of bacteria by gas chromatography. Appl. Microbiol. 14:513-524.

10. Henriksen, S. D. 1969. Corroding bacteria from the respiratory tract. 2. Bacteroides corrodens. Acta Pathol. Scand. 75:91-96.

11. Henriksen, S. D. 1969. Designation of the type strain of Bacteroides corrodens Eiken 1958. Int. J. Syst. Bacteriol. 19:165-166.

12. Ifkovits, R. W., and H. S. Ragheb. 1968. Cellular fatty acid composition and identification of rumen bacteria. Appl. Microbiol. 16:1406-1413.

13. Jackson, F. L., and Y. E. Goodman. 1972. Transfer of the facultatively anaerobic organism Bacteroides corrodens Eiken to a new genus, Eikenella. Int. J. Syst. Bacteriol. 22:73-77.

14. Jackson, F. L., Y. E. Goodman, F. R. Bel, P. C. Wong, and R. L. S. Whitehouse. 1971. Taxonomic status of facultative and strictly anaerobic "corroding bacilli' that have been classified as $\mathrm{BaC}$ teroides corrodens. J. Med. Microbiol. 4:171-184.

15. James. A. T. 1960. Qualitative and quantitative determination of fatty acids by gas-liquid chromatography. Methods Biochem. Anal. 8: 1-59.

16. Kaneda, T. 1968. Fatty acids in the genus Bacillus. II. Similarity in the fatty acid compositions of Bacillus thuringiensis, Bacillus anthracis, and Bacillus cereus. J. Bacteriol. 95: 2210-2216.

17. Khairat, O. 1967. Bacteroides corrodens isolated from bacteriaemias. J. Pathol. Bacteriol. $94: 2940$.

18. Loesche, W. J. 1969. Oxygen sensitivity of various anaerobic bacteria. Appl. Microbiol. 18:723-727.

19. Marr, A. G., and J. L. Ingram. 1962. Effect of temperature on the composition of fatty acids in Escherichia coli. J. Bacteriol. 84:1260-1267.

20. Rosebury, T. 1962. Microorganisms indigenous to man. McGraw-Hill, New York.

21. Talbot, J. M., and P. H. A. Sneath. 1960. Taxonomic study of Pasteurella septica especially strains from human sources. J. Gen. Microbiol. 22:303-311.

22. Vaczi, L., J. Redai, and A. Rethy. 1967. Changes in the fatty acid composition of Staphylococcus aureus under various cultural conditions. Acta Microbiol. Acad. Sci. Hung. 14:293-298.

23. Van Loghem, J. J. 1946. La classification du Bacille pesteux. Ann. Inst. Pasteur 72:975.

24. Wahren, A., and T. Holme. 1969. Growth of Bacteroidaceae in stirred fermentors. Appl. Microbiol. 18:235-239. 